\title{
DNA methylation profiling identifies novel markers of progression in hepatitis B-related chronic liver disease
}

\author{
Müjdat Zeybel ${ }^{1,2^{*}}$, Sezgin Vatansever ${ }^{3}$, Timothy Hardy ${ }^{1}$, Ayşegül Akder Sarı ${ }^{4}$ Fulya Cakalağaoğlư ${ }^{4}$, Arzu Avcl, \\ Gemma Louise Zeybel', Serçin Karahüseyinoğlư ${ }^{2}$, Matthew Bashton ${ }^{5}$, John C. Mathers ${ }^{6}$, Belkıs Ünsal ${ }^{3 \dagger}$ and Jelena Mann ${ }^{1+}$
}

\begin{abstract}
Background: Chronic hepatitis B infection is characterized by hepatic immune and inflammatory response with considerable variation in the rates of progression to cirrhosis. Genetic variants and environmental cues influence predisposition to the development of chronic liver disease; however, it remains unknown if aberrant DNA methylation is associated with fibrosis progression in chronic hepatitis B.

Results: To identify epigenetic marks associated with inflammatory and fibrotic processes of the hepatitis B-induced chronic liver disease, we carried out hepatic genome-wide methylation profiling using Illumina Infinium BeadArrays comparing mild and severe fibrotic disease in a discovery cohort of 29 patients. We obtained 310 differentially methylated regions and selected four loci comprising three genes from the top differentially methylated regions: hypermethylation of HOXA2 and HDAC4 along with hypomethylation of PPP1R18 were significantly linked to severe fibrosis. We replicated the prominent methylation marks in an independent cohort of 102 patients by bisulfite modification and pyrosequencing. The timing and causal relationship of epigenetic modifications with disease severity was further investigated using a cohort of patients with serial biopsies.

Conclusions: Our findings suggest a linkage of widespread epigenetic dysregulation with disease progression in chronic hepatitis B infection. CpG methylation at novel genes sheds light on new molecular pathways, which can be potentially exploited as a biomarker or targeted to attenuate inflammation and fibrosis.
\end{abstract}

Keywords: Epigenetics, Liver fibrosis, DNA methylation, Cirrhosis, Hepatitis B infection

\section{Background}

Hepatitis B is the one of the leading causes of chronic liver disease; 350 million people are chronically infected by the hepatitis $B$ virus worldwide [1]. It has been estimated that hepatitis B infection is responsible for more than 500,000 deaths annually and is the 15th most common cause of death globally $[2,3]$. Chronic hepatitis B infection is characterized by immune-mediated liver damage leading to necroinflammation and accumulation of fibrotic tissue. Persistent viral replication and repetitive hepatic injury

\footnotetext{
* Correspondence: mzeybel@ku.edu.tr

${ }^{\dagger}$ Equal contributors

${ }^{1}$ Institute of Cellular Medicine, Newcastle University, Newcastle upon Tyne, UK

${ }^{2}$ School of Medicine, Koç University Hospital, Koç University, 4th floorM-4220. Davutpaşa Caddesi no: 4, 34010 Istanbul, Turkey

Full list of author information is available at the end of the article
}

may ultimately evolve into cirrhosis, together with substantially increased risk of adverse clinical outcomes such as liver failure, portal hypertension and hepatocellular carcinoma [4].

Hepatic inflammation and fibrotic processes comprise complex cellular and molecular interactions. Progression from chronic hepatic inflammation to the fibrotic/cirrhotic stage is underpinned by numerous core pathways, observed in other fibrotic diseases, as well as tissue- or injury-specific pathways that are only activated in particular conditions [5, 6]. Depending on the activity of such mechanisms, progression to fibrosis varies significantly among hepatitis B-infected individuals, as in other liver disorders [4]. To date, several studies have linked genetic and environmental factors to the propensity towards hepatic fibrosis progression. Genetic polymorphisms 
(patatin-like phospholipase domain-containing protein 3 (PNPLA3), transmembrane 6 superfamily member 2 (TM6SF2), seven-gene signatures) have been particularly associated with the susceptibility of advanced liver disease in non-alcoholic fatty liver disease and chronic hepatitis C infection [7-11]. While the influence of genetic variants in hepatitis B-associated chronic liver disease is less clearly established, a recent study indicated that the rs12979860 polymorphism of interferon- $\lambda$ is consistently linked to hepatic fibrosis in liver diseases including chronic hepatitis B infection [12].

DNA methylation is the addition of methyl group to a fifth carbon of cytosine residues within a CG dinucleotide, frequently referred to as cytosine-guanine dinucleotide (CpG). This type of DNA methylation is an essential component of epigenetic machinery that regulates the transcriptional state, alongside histone modifications and microRNAs. As a transcriptional regulator, DNA methylation has a considerable impact on the development of common diseases and cancer [13, 14]. Epigenetic mechanisms are dynamically regulated throughout the lifetime and act as an interphase between genetic background and environmental cues. CpG methylation-mediated transcriptional control and epigenetic dysregulation have also been implicated as an important contributing factor in liver diseases including non-alcoholic fatty liver disease and alcoholic liver disease $[15,16]$. However, it is not known whether epigenetic signatures influence progression of hepatitis B-related liver disease. We hypothesized that epigenetic signatures can be associated with liver disease progression, and in order to define epigenetic patterns in early and advanced stages of inflammation and fibrosis, we performed an hepatic DNA methylome analysis using liver specimens of chronic hepatitis B patients. Alterations in DNA methylome were further investigated and replicated in the independent cohort and in the cohort of patients with sequential biopsies.

\section{Results and discussion}

To identify DNA methylation alterations in hepatitis Binduced liver disease, we conducted an epigenome-wide mapping using Infinium HumanMethylation450 BeadChip platform. Our discovery cohort included 29 hepatitis B virus (HBV)-infected patients allocated into either a mild fibrosis group (13 patients, fibrosis stage $\leq 2)$ or severe fibrosis group (16 patients, fibrosis stage $\geq 3$ ) (for study design, please see Additional file 1: Figure S1). To minimize the effect of the immune stage of the disease, only hepatitis e antigen-negative patients were included into the discovery cohort. The clinical characteristics, histological activity and staging of the discovery cohort are provided in Table 1. Baseline demographics revealed no significant differences between mild and severe groups. The mean $\mathrm{CpG}$ sites detected across the study
Table 1 Baseline characteristics of the discovery cohort

\begin{tabular}{|c|c|c|c|}
\hline & $\begin{array}{l}\text { Mild fibrosis } \\
\text { (F0-2) }\end{array}$ & $\begin{array}{l}\text { Severe fibrosis } \\
\text { (F3-6) }\end{array}$ & $P$ value \\
\hline & $n=16$ & $n=13$ & \\
\hline Gender-male ${ }^{a}$ & $9(56.2)$ & $8(61.5)$ & ns \\
\hline Age $\left(\right.$ years) ${ }^{a}$ & $48.2 \pm 14.7$ & $54.2 \pm 11.6$ & ns \\
\hline Hbe Ag positive ${ }^{a}$ & $-(0)$ & $-(0)$ & ns \\
\hline Anti Hbe Ab positive ${ }^{a}$ & $16(100)$ & $13(100)$ & - \\
\hline HBV DNA $(\log I U / m L)^{b}$ & $6.2 \pm 5.8$ & $8.5 \pm 4.7$ & ns \\
\hline Serum ALT (IU/L) $)^{b}$ & $56.5 \pm 35.6$ & $106.2 \pm 87.1$ & ns \\
\hline Serum AST $(I U / L)^{b}$ & $41.7 \pm 29.1$ & $75.1 \pm 56.1$ & 0.01 \\
\hline $\begin{array}{l}\text { White blood cell count } \\
\left(\times 10^{9} / L\right)^{b}\end{array}$ & $6.2 \pm 1.2$ & $5.6 \pm 1.4$ & ns \\
\hline Platelet count $\left(\times 10^{9} / L\right)^{b}$ & $218.9 \pm 52.1$ & $177.9 \pm 64.54$ & ns \\
\hline Haemoglobin $(\mathrm{g} / \mathrm{L})^{\mathrm{b}}$ & $13.8 \pm 0.9$ & $13.6 \pm 1.6$ & ns \\
\hline Albumin $(g / L)^{b}$ & $4.4 \pm 0.3$ & $4.4 \pm 0.4$ & ns \\
\hline Prothrombin time $(s)^{b}$ & $11.8 \pm 0.8$ & $12.1 \pm 0.9$ & ns \\
\hline Direct bilirubin $(\mathrm{mg} / \mathrm{dL})^{\mathrm{b}}$ & $0.31 \pm 0.1$ & $0.37 \pm 0.1$ & ns \\
\hline \multicolumn{4}{|l|}{$\begin{array}{l}\text { Modified histologic activity } \\
\text { index }\end{array}$} \\
\hline $0-4$ & $9(56.25)$ & $2(15.3)$ & \\
\hline $5-9$ & $7(43.75)$ & $9(69.23)$ & \\
\hline $10-14$ & - & $2(15.3)$ & \\
\hline $15-18$ & - & - & \\
\hline \multicolumn{4}{|l|}{ Fibrosis $^{\mathrm{a}}$} \\
\hline 0 & $9(56.25)$ & - & \\
\hline 1 & $2(12.5)$ & - & \\
\hline 2 & $5(31.25)$ & - & \\
\hline 3 & - & $4(30.7)$ & \\
\hline 4 & - & $3(23.0)$ & \\
\hline 5 & - & $4(30.7)$ & \\
\hline 6 & - & $2(15.3)$ & \\
\hline
\end{tabular}

a,b Data are shown as number and percentage $\left({ }^{\mathrm{a}}\right)$ or mean and standard deviation $\left({ }^{b}\right)$. The histologic activity index is a sum of portal inflammation, confluent necrosis, focal lytic necrosis and periportal or periseptal interface hepatitis scores which was expressed on a scale of 18. Fibrosis stage was assessed on a scale of 0 to 6

group was 462,891 . We identified a total of 310 differentially methylated regions between the mild and severe groups; 109 of them were significantly hypermethylated, and 201 were hypomethylated in the advanced group. Top-ranked 40 differentially methylated regions are summarized in Additional file 2: Table S1; which includes HLA-DQA1 (major histocompatibility complex, class II, DQ alpha 1), TMEM57 (transmembrane protein 57) and HDAC4 (histone deacetylase 4). Differentially methylated position analysis revealed that 18,234 probes showed significant methylation differences between the two groups; 11,475 loci were associated with higher amounts of methylation and 6759 loci were hypomethylated in the 
severe fibrosis group. The top 20 hypermethylated and hypomethylated probes associated with disease severity are provided in Additional file 3: Table S2 and Additional file 4: Table S3. Figure 1 illustrates the main characteristics of the breakdown of the $\mathrm{CpG}$ sites in relation to transcripts and clusters of $\mathrm{CpG}$ sites (CpG islands). Hypomethylated CpG sites in advanced disease were more frequently located within or close proximity to CpG islands (31.3 vs $14.7 \%$ ) and transcription start sites (29.3 vs $16.5 \%$ ).

Using bioinformatics assessment and pathway analysis, we identified two individual CpG sites which were strongly associated with the disease progression: cg13985518 (chr7:27143788, HOXA2 (homeobox A2), CpG site located within 1500 base pairs of transcription start site) and cg20690667 (chr6:30652228, PPP1R18 (protein phosphatase 1 , regulator subunit 18 ), CpG site positioned within the gene body-1st exon). Further analysis on differentially methylated regions showed that the HDAC4 gene body (chr2:240241154-240241218) is markedly hypermethylated in the severe group $(P=0.002)$. We further designed pyrosequencing assays to test relevant or nearby CpGs in HOXA2 and PPP1R18 genes and two CpGs in the HDAC4 gene (chr2:240241209-CpG1 and 240241218CpG2, CpG sites are located in the gene body) by locus-
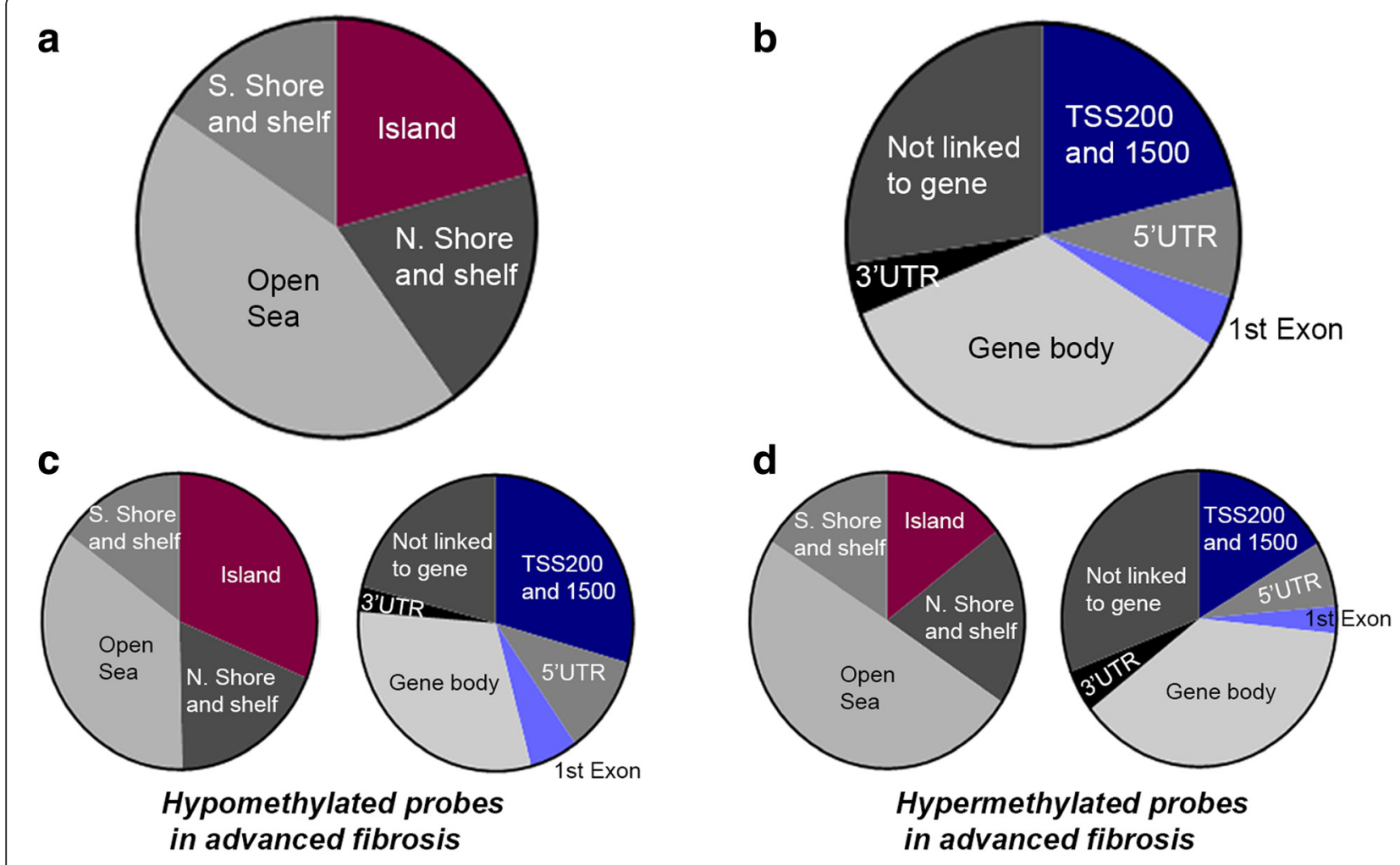

e

\begin{tabular}{|l|c|c|c|c|c|c|}
\hline & \multicolumn{2}{|c|}{$\begin{array}{c}\text { total } \\
\%\end{array}$} & \multicolumn{2}{c|}{$\begin{array}{c}\text { Hypomethylated } \\
\text { Probes (\%) }\end{array}$} & $\begin{array}{c}\text { Hypermethylated } \\
\text { Probes (\%) }\end{array}$ \\
\hline Island & 3801 & 20,8 & 2114 & 31,3 & 1687 & 14,7 \\
\hline N. Shelf & 999 & 5,5 & 265 & 3,9 & 734 & 6,4 \\
\hline N. Shore & 2498 & 13,7 & 981 & 14,5 & 1517 & 13,2 \\
\hline Open Sea & 8082 & 44,3 & 2386 & 35,3 & 5696 & 49,6 \\
\hline S. Shelf & 895 & 4,9 & 219 & 3,2 & 676 & 5,9 \\
\hline S. Shore & 1959 & 10,7 & 794 & 11,7 & 1165 & 10,2 \\
\hline
\end{tabular}

\section{f}

\begin{tabular}{|l|c|c|c|c|c|c|}
\hline & \multicolumn{2}{|c|}{$\begin{array}{c}\text { total } \\
\text { \% }\end{array}$} & \multicolumn{2}{c|}{$\begin{array}{c}\text { Hypomethylated } \\
\text { Probes (\%) }\end{array}$} & \multicolumn{2}{c|}{$\begin{array}{c}\text { Hypermethylated } \\
\text { Probes (\%) }\end{array}$} \\
\hline TS1500 & 2584 & 14,2 & 1250 & 18,5 & 1334 & 11,6 \\
\hline TS200 & 1296 & 7,1 & 733 & 10,8 & 563 & 4,9 \\
\hline 5'UTR & 1547 & 8,5 & 733 & 10,8 & 814 & 7,1 \\
\hline 1st Exon & 725 & 4,0 & 382 & 5,7 & 343 & 3,0 \\
\hline Gene body & 6403 & 35,1 & 2055 & 30,4 & 4348 & 37,9 \\
\hline 3'UTR & 721 & 4,0 & 185 & 2,7 & 536 & 4,7 \\
\hline Not linked to gene & 4958 & 27,1 & 1421 & 21,0 & 3537 & 30,8 \\
\hline
\end{tabular}

Fig. 1 a The pie chart shows differentially methylated probes in advanced versus mild fibrosis according to UCSC classification of CpG islands: Island (CpG island), N. Shore and shelf (2-kb upstream of CpG islands and 2-4-kb upstream of CpG islands, flanking regions of shores), Open Sea, S. Shore and shelf (2-kb downstream of CpG islands and flanking regions of shores). $\mathbf{b}$ Pie chart illustrates probes with methylation differences in advanced versus mild according to functional regions: TSS200 and 1500 (200- and 1500-bp upstream of transcription start sites; annotated promoters), 5'UTR (5' untranslated region), 1st Exon, Gene body, 3'UTR (3' untranslated region). c Pie charts show hypomethylated probes in advanced inflammation and fibrosis in comparison to mild fibrosis according to CpG clusters and functional regions. d Pie charts show hypermethylated probes in advanced inflammation and fibrosis in comparison to mild fibrosis according to CpG clusters and functional regions. e-f Number and percentages of differentially methylated probes 
specific DNA methylation analysis in the discovery cohort (Fig. 2). Validation plots of primer sets are provided in Additional file 5: Figure S2; the assays gave satisfactory results with $r^{2}$ values over 0.95 . We obtained similar DNA methylation changes in HOXA2, PPP1R18 and HDAC4 genes ( $P$ values are $0.01,0.01,0.01$ and 0.007 , respectively) as shown in Fig. 2. We also examined the protein levels and localisation of HDAC4 in liver sections of hepatitis B patients (Additional file 6: Figure S3). In the early stages of inflammation and fibrosis, $H D A C$ expression was barely detectable in hepatocytes. HDAC4 positivity was detected in myofibroblast-like cells, inflammatory and biliary cells and hepatocytes adjacent to fibrosis tracts in hepatitis B-induced cirrhosis (Additional file 6: Figure S3).

We assessed the association of the newly discovered DNA methylation changes in a larger cohort comprising 102 retrospectively recruited patients; in this cohort, 70 patients had mild (Ishak fibrosis stage 0-2) and 32 had severe liver disease (Ishak fibrosis stage 3-6) due to chronic hepatitis B infection. The patient characteristics according to the fibrosis stage are shown in Table 2. Similarly, epigenetic examination was conducted using bisulfite modification and pyrosequencing analysis. As illustrated in Fig. 3, marked increase in HOXA2 DNA methylation was demonstrated in the severe fibrosis group versus the mild group (chr7:27143806, mean \pm SE, $48.8 \pm 2.0$ vs $58.9 \pm 2.5$ ); conversely, significantly lower CpG methylation values were detected in advanced disease at the PPP1R18 gene (chr6:30652228, mean \pm SE, $34.1 \pm 2.9$ vs $24.5 \pm 3.7)$. Elevated methylation levels in the HDAC4 gene body associated with progression of necroinflammation and fibrosis were confirmed in previously described two loci (chr2:240241209, $17.5 \pm 2.0$ vs $25.89 \pm 3.27$ and chr2:240241218, $18.7 \pm 5.0$ vs $35.6 \pm 5.2$ ).

Given the dynamic status of epigenetic modifications, we next considered whether methylation variations in the observed regions developed as a consequence of disease progression. To assess the causality and association of epigenetic imprints, we performed methylation analysis in a cohort of patients with sequential biopsies. Patients were included either into the progressor group (fibrosis stage was increased between two biopsies) or into the non-progressor group (fibrosis stage remained stable) (Additional file 7: Table S4). The comparison of DNA methylation analysis in two groups demonstrated that methylation signatures were not different at initial biopsies (Fig. 4). We further examined the methylation changes using initial and follow-up biopsies. This analysis indicated that only $H O X A 2$ methylation was increased in the progression of hepatitis B-induced chronic liver disease (Additional file 8: Figure S4).
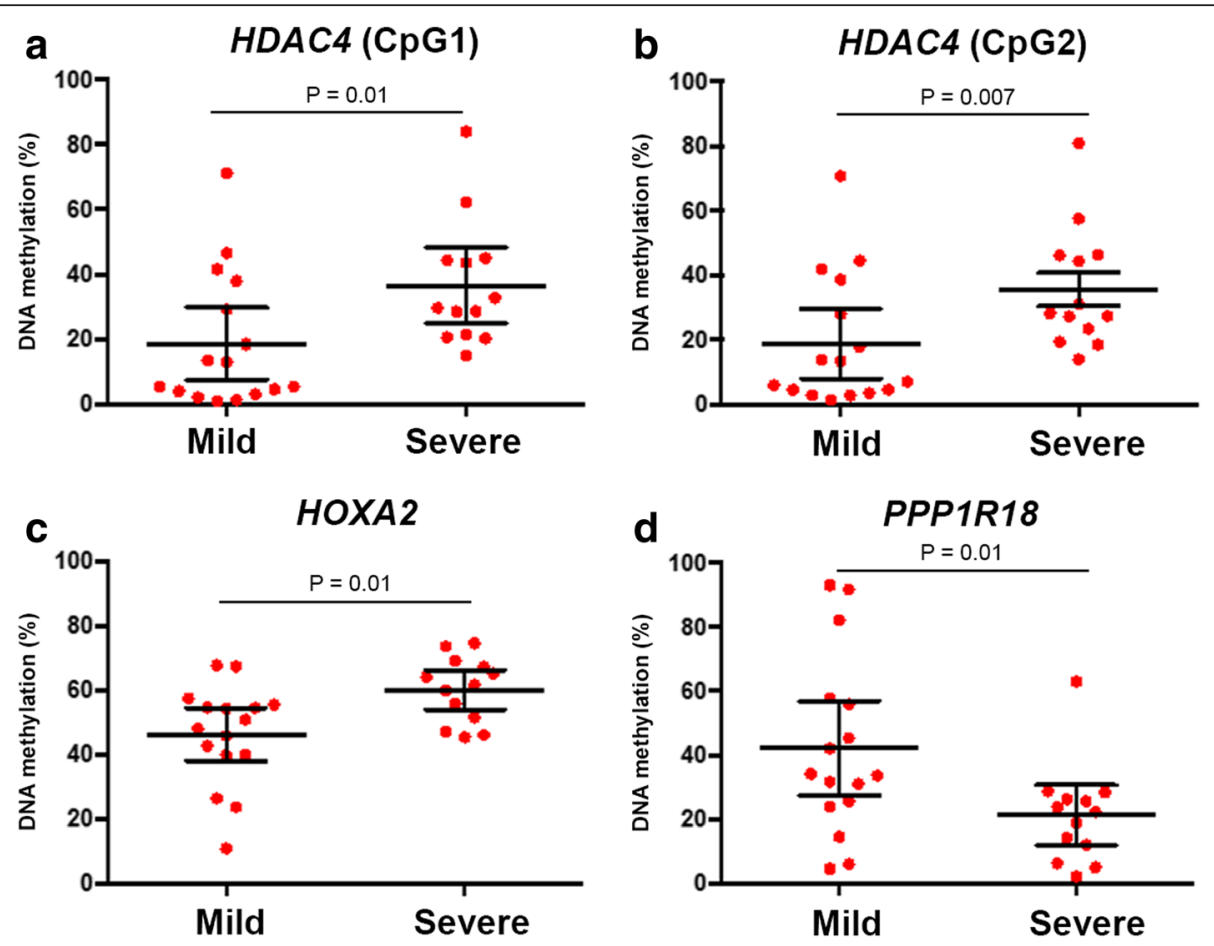

Fig. 2 Plots were demonstrated as the correlation between the CpG methylation and severity of the liver disease. The analysis compares the hepatic DNA methylation level in the Ishak fibrosis stages of F0-2 with F3-6. Horizontal bars represent the means and $95 \%$ confidence interval. Using bisulfite modification and pyrosequencing, hepatic cytosine methylation at four loci was assessed. Changes in HDAC4 (a, b), HOXA2 (c) and PPP1R18 (d) CpG methylation are associated with severe inflammation and fibrosis in the discovery cohort 
Table 2 Baseline characteristics of the validation cohort

\begin{tabular}{|c|c|c|c|}
\hline & $\begin{array}{l}\text { Mild fibrosis } \\
(\mathrm{F} 0-2)\end{array}$ & $\begin{array}{l}\text { Severe fibrosis } \\
\text { (F3-6) }\end{array}$ & $P$ value \\
\hline & $n=70$ & $n=32$ & \\
\hline Gender-male ${ }^{a}$ & $33(47.1)$ & $20(62.5)$ & ns \\
\hline Age (years) ${ }^{a}$ & $45.6 \pm 13.7$ & $50.28 \pm 11.25$ & ns \\
\hline Hbe Ag positive ${ }^{a}$ & 16 & 6 & ns \\
\hline Anti $\mathrm{Hbe}$ Ab positive ${ }^{a}$ & 54 & 26 & \\
\hline HBV DNA $(\log I U / m L)^{b}$ & $7.4 \pm 4.3$ & $7.0 \pm 2.5$ & ns \\
\hline Serum ALT (IU/L) $)^{b}$ & $70.5 \pm 48.0$ & $83.0 \pm 59.87$ & ns \\
\hline Serum AST $(I U / L)^{b}$ & $45.1 \pm 22.5$ & $64.28 \pm 47.3$ & ns \\
\hline White blood cell count $\left(\times 10^{9} / L\right)^{b}$ & $6.4 \pm 1.5$ & $6.3 \pm 1.7$ & ns \\
\hline Platelet count $\left(\times 10^{9} / L\right)^{b}$ & $207.7 \pm 45.6$ & $196.5 \pm 42.8$ & ns \\
\hline Haemoglobin $(g / L)^{b}$ & $14.0 \pm 1.7$ & $14.5 \pm 1.3$ & ns \\
\hline Albumin $(g / L)^{b, c}$ & $4.4 \pm 0.3$ & $4.4 \pm 0.3$ & ns \\
\hline Prothrombin time $(s)^{b, c}$ & $11.4 \pm 1.6$ & $11.5 \pm 2.5$ & ns \\
\hline Conjugated bilirubin $(\mathrm{mg} / \mathrm{dL})^{\mathrm{b}, \mathrm{c}}$ & $0.19 \pm 0.18$ & $0.26 \pm 0.25$ & ns \\
\hline \multicolumn{4}{|l|}{ Modified histologic activity index ${ }^{a}$} \\
\hline $0-4$ & $47(67.1)$ & $1(3.1)$ & - \\
\hline $5-9$ & $22(31.4)$ & 25 (78.1) & - \\
\hline $10-14$ & $1(1.4)$ & $5(15.6)$ & - \\
\hline $15-18$ & - & $1(3.1)$ & - \\
\hline Fibrosis $^{a}$ & & & - \\
\hline 0 & $33(47.1)$ & - & - \\
\hline 1 & $20(28.5)$ & - & - \\
\hline 2 & $17(24.2)$ & - & - \\
\hline 3 & - & $20(62.5)$ & - \\
\hline 4 & - & $5(15.6)$ & - \\
\hline 5 & - & $5(15.6)$ & - \\
\hline 6 & - & $2(6.2)$ & - \\
\hline
\end{tabular}

a,b Data are shown as number and percentage $\left({ }^{\mathrm{a}}\right)$ or mean and standard deviation $\left({ }^{b}\right)$. The histologic activity index is a sum of portal inflammation, confluent necrosis, focal lytic necrosis and periportal or periseptal interface hepatitis scores which was expressed on a scale of 18. Fibrosis stage was assessed on a scale of 0 to 6

Information on conjugated bilirubin, prothrombin time and albumin was missing in six, two, and five patients, respectively

To our knowledge, this is the first epigenome-wide methylation study comparing mild and severe hepatitis Brelated liver disease. Analysis of genome-wide differentially methylated $\mathrm{CpG}$ sites and regions in the discovery cohort revealed widespread alterations in the DNA methylome in the progression of chronic liver disease; 310 differentially methylated regions (109 hypermethylated CpG sites and 201 hypomethylated CpG sites) were linked to severe hepatic inflammation and fibrosis. We identified hypermethylation of three loci in HDAC4 and HOXA2 genes and a less methylated CpG site in the PPP1R18 gene in HBVassociated advanced liver fibrosis. Epigenetic differences at four newly identified CpG sites have not previously been linked with chronic liver disease. Observed differences were also confirmed by bisulfite conversion and pyrosequencing in an independent patient cohort. Prior studies on epigenetics of chronic liver disease and hepatocellular carcinoma have noted the importance of DNA methylation in disease development $[17,18]$. Furthermore, recent research also suggests that hepatitis B infection induces genome-wide methylation changes in hepatocytes $[19,20]$. The current study, while supporting previous findings, also expands our understanding of methylome alterations in histologically proven hepatitis B-induced inflammation and fibrosis.

HDAC4 is a member of class II histone deacetylases and is located in both nuclear and cytoplasmic compartments of cells. Methylation differences in the HDAC4 gene have a particular importance, since HDAC4 executes deacetylation of histone proteins and changes chromatin configuration, which results in transcriptional repression. Given that CpG methylation in the gene body is frequently observed in transcriptionally active genes, higher expression of HDAC4 might be expected in the severe liver disease group [21]. Indeed, we observed the abundance of $H D A C 4$ expression in fibrosis tracts of hepatitis B-cirrhosis; conversely, it was significantly less expressed in mild disease. It is likely that the presence of CpG methylation within the HDAC4 gene may lead to the removal of acetyl groups from histone tails, further repressing transcription. The results of this study are consistent with recent in vitro studies indicating that $H D A C 4$ plays a key role in myofibroblastic differentiation and fibrogenesis [22]. Furthermore, there is growing evidence that pharmacological inhibition of HDACs by trichostatin A, largazole or valproic acid suppresses fibrogenesis in primary hepatic stellate cells and animal models of liver fibrosis [23-25]. Crosstalk between DNA methylation and histone modifications has been studied extensively [26]. This study raises the possibility that a multifaceted interplay of epigenetic mechanisms may control the progression of chronic liver disease. A potential complementary mechanism for regulation of inflammation and matrix remodelling may be the interaction of genetic variations and epigenetic machineries, e.g. the presence of single nucleotide polymorphisms at the HDAC gene may be a promising tool to predict treatment response in chronic hepatitis $\mathrm{C}$ infection [27].

HOXA2 is part of the HOXA transcription factor cluster which has an important role in cell differentiation, embryonic development and cancer. Recent studies suggest that HOXA cluster gene expression is under epigenetic control; it is repressed by epigenetic imprints including 5methylcytosines [28]. Similar epigenetic linkage of the HOXA cluster was observed in hepatic malignancies; aberrant methylation of $H O X A 2$ CpG islands is often associated with cholangiocarcinoma [29]. DNA methylation in promoter regions and CG-rich regions is 

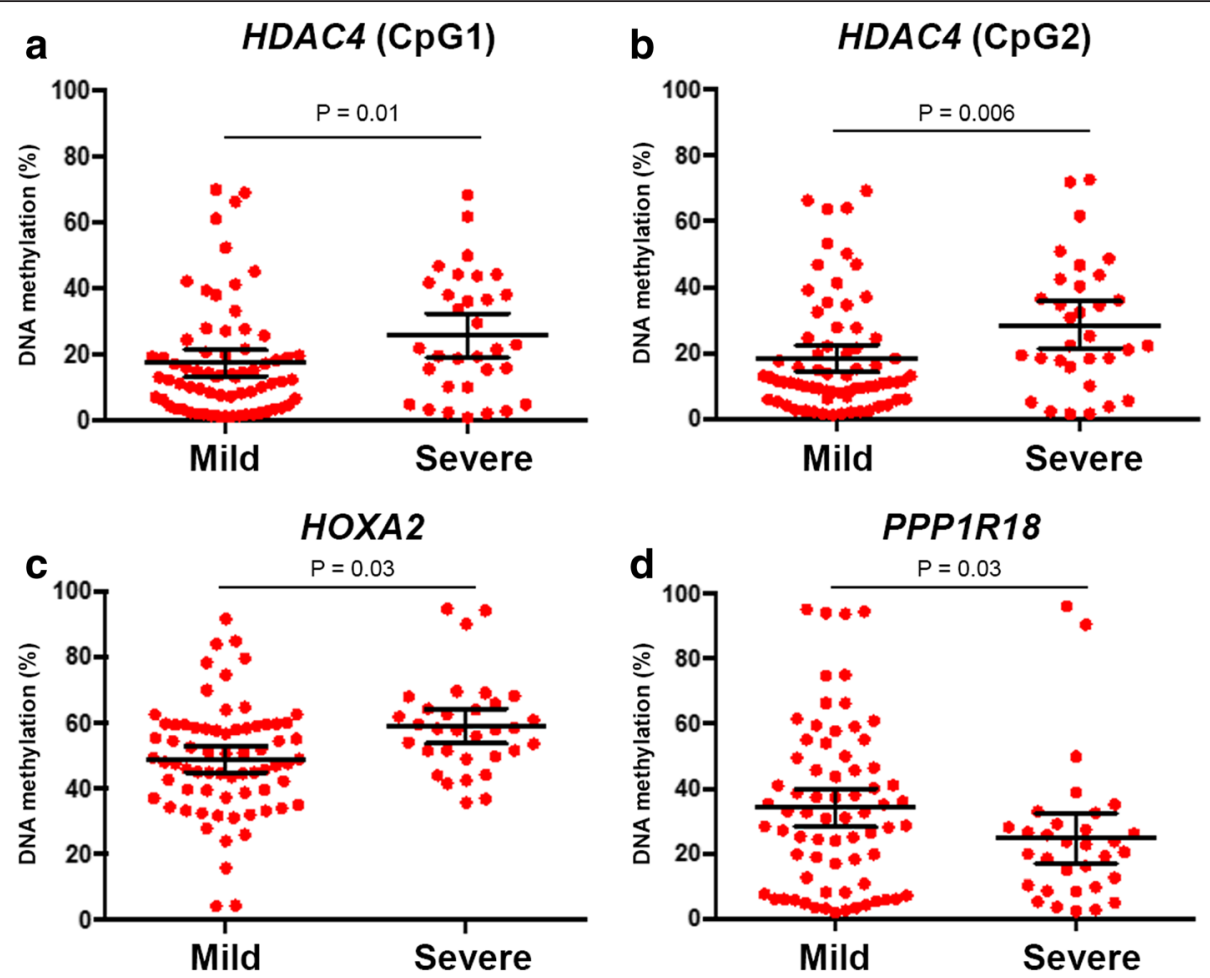

Fig. 3 Plots were demonstrated as the correlation between the CpG methylation and severity of the liver disease. The analysis compares hepatic DNA methylation level in F0-2 with F3-6 according to Ishak staging. Horizontal bars represent the means and $95 \%$ confidence interval. Higher hepatic HDAC4 (a, b) and HOXA2 (c) methylation and lower PPP1R18 (d) methylation indicates advanced necroinflammation and fibrosis
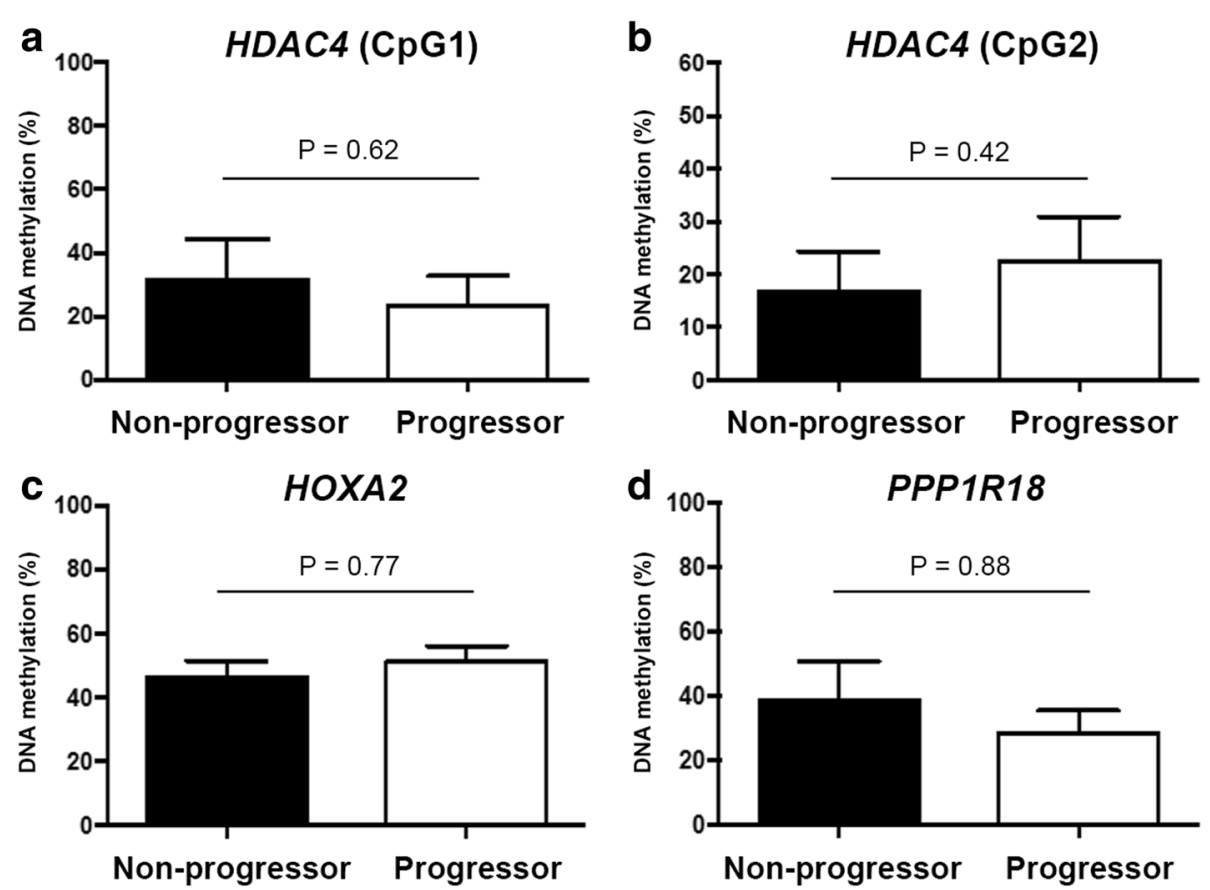

Fig. 4 Hepatic DNA methylation levels from initial biopsies of non-progressors (no increase in stage of fibrosis) and progressors ( $\geq 1$ stage increase in severity of fibrosis). Boxes and bars represent the means and standard error, respectively. Cytosine methylation at HDAC4 (a, b), HOXA2 (c) and PPP1R18 (d) genes did not differ significantly between the two groups 
frequently associated with gene silencing; since we obtained hypermethylation of the HOXA2 locus within 1500 base pairs of the transcription start site in the current study, this may lead to repression of the HOXA2 gene in advanced liver disease. Future studies will be needed to characterize a comprehensive function for HOXA2 in viral-hepatitis-related liver disease. The PPP1R18 gene (also referred as KIAA1949) encodes a phostensin protein which is localized closely with cytoskeletal proteins such as actin filaments. Phostensin is mainly expressed in lymphocytes, monocytes and macrophages and shown in many tissues, but higher expression is detected in the spleen and other lymphatic tissues [30, 31]. Since lower methylation levels were obtained in the first exon of the PPP1R18 gene, it is likely that phostensin is up-regulated around inflammatory and fibrotic milieu in correlation with disease severity.

Epigenetic modifications can be dynamically regulated, both in development and disease. In this study, we were not able to determine if the observed epigenetic differences are the cause or the consequence of the disease process. It is likely that our observed patterns of methylation, particularly in CpG-rich gene regulatory regions, can modulate inflammatory and fibrogenic pathways; equally, epigenetic marks could have been acquired subsequently as an outcome of advanced disease. Moreover, contribution of heritable epigenetic factors to liver fibrogenesis has recently been described; therefore, it is also possible that epigenetic signatures can be inherited across generations and modify hepatic disease outcome [32, 33]. Data from the initial biopsies of our follow-up cohort support the idea that DNA methylation variations may be developed with disease progression. Indeed, we observed a modest increase in HOXA2 methylation in progressors compared to mild reduction in non-progressors. Nevertheless, it is difficult to reach a definite conclusion due to the limited sample size.

It is important to note that this epigenetic study was performed using liver needle biopsy samples that contain several cell types including hepatocytes, myofibroblasts, endothelial cells, macrophages and other inflammatory cells. In line with all other epigenetic modifications, it is likely that some methylated cytosines are cell type-specific, which can impact on the precision of the epigenome-wide studies such as this [34]. Another limitation of the study was the use of moderate sample size in the discovery cohort. We aimed to overcome this issue by using a larger validation cohort to confirm the initial results. Indeed, all four CpG sites were replicated in the validation cohort. It is also worth noting that in our study we employed liver needle biopsy samples, which can represent 1/50,000 of the whole liver. Sampling variability is therefore another issue that has previously been observed in the evaluation of chronic liver disease [35]. We have previously shown that CpG methylation levels are rather consistent across the liver; therefore, sampling error appears to be less of a problem, at least for hepatic DNA methylation [16].

Exploring the epigenetic and cellular basis of chronic liver disease progression is undoubtedly important. There is a growing tendency towards the use of epigenetic modifications as biomarkers of disease in clinical settings. Furthermore, it is also likely that DNA methylation blueprint from the blood or liver may have utility in diagnosing inflammatory or fibrotic status of the liver [36]. A recently published study suggests that the PPAR $\gamma$ promoter hypermethylation in peripheral blood mononuclear cells is associated with severe inflammation and fibrosis in chronic hepatitis B [37]. Our research also suggests that PPAR $\gamma$ promoter hypermethylation of cell-free DNA is a promising biomarker for non-invasive diagnosis of fibrosis in non-alcoholic fatty liver disease [38]. Viral hepatitis-induced chronic liver disease is slowly progressive and a particularly heterogeneous clinical condition. Stratification of patients, and establishment of personalized medicine, needs significant improvement which may be overcome by implementation of DNA methylation markers. Moreover, the highly dynamic nature of epigenetic markers makes them suitable drug targets. Future therapeutic strategies may include the modulation of novel genes involved in inflammation and fibrosis. Further research is required to broaden the mechanistic role of DNA methylation in chronic liver disease.

\section{Conclusions}

In conclusion, we found novel epigenetic signatures associated with hepatic inflammation fibrosis in HBVrelated liver disease. These epigenetically modified genes may be linked with liver disease progression and could provide further insights into the pathogenesis of chronic liver disease. Progression-associated CpG sites within HOXA2, PPP1R18 and HDAC4 genes might have clinical utility as a prognostic marker of $\mathrm{HBV}$-induced chronic liver disease.

\section{Methods}

A total of 131 patients with chronic HBV infection were identified and included retrospectively into the study from a single centre (Katip Çelebi University, Atatürk Eğitim ve Araştırma Hastanesi, Izmir, Turkey). Patients were selected based on the medical records with a positivity for hepatitis B surface antigen ( $\mathrm{HbsAg}$ ) for longer than 6 months and who have undergone percutaneous liver biopsy. Patients that received antiviral therapy in the last 6 months, presence of hepatitis delta infection, hepatitis $\mathrm{C}$ infection, non-alcoholic fatty liver disease, drug-induced liver injury, autoimmune liver disease, hereditary hemochromatosis, $\alpha 1$-antitrypsin deficiency or an average alcohol consumption of over $20 \mathrm{~g}$ daily for 
men and over $10 \mathrm{~g}$ for women were excluded from the study. Patients with concomitant human immunodeficiency virus (HIV) infection and/or hepatocellular carcinoma were also excluded from the study.

Formalin-fixed paraffin-embedded (FFPE) percutaneous needle liver biopsy specimens were stained with haematoxylin and eosin and picrosirius red/Masson's trichrome (data not shown). Hepatic inflammatory activity and the fibrosis stage were assessed according to the Ishak system by expert pathologists [39]. The following demographic and clinical laboratory parameters were obtained from medical records: age, sex, aspartate aminotransferase, alanine aminotransferase, conjugated bilirubin, albumin, prothrombin time, complete blood count, $\mathrm{HbeAg}$, anti-Hbe $\mathrm{Ab}$ and circulating HBV DNA levels. Genomic DNA was extracted from FFPE needle biopsy samples by QIAamp DNA microkit (Qiagen) and QIA DNA FFPE tissue kit (Qiagen) as recommended by the manufacturer and stored at $-80{ }^{\circ} \mathrm{C}$. DNA quality and quantity was assessed by Nanodrop 1000 (Thermo Scientific). DNA samples were hybridized on the Infinium 450K BeadChip (Illumina, San Diego, USA) to evaluate genome-wide DNA methylation. $1 \mu \mathrm{g}$ DNA was used for bisulfite conversion and repaired by Infinium HD FFPE restore kit (Illumina, San Diego, USA). Amplification and hybridization of samples were performed according to the manufacturer's protocol. Infinium HumanMethylation450 BeadChip platform data was analysed and processed using Bioconductor minfi package (www.bioconductor.org) [40]. It employs Storey FDR correction [41] where differentially methylated regions are detected using a permutation test, which means the $P$ values returned are inherently robust to false discovery. Additionally, during analysis, we used 10,000 permutations, which give a very robust answer, given that the standard default for such analysis is 1000 . CpG methylation values for each of the samples were obtained as $\beta$ values. Quality control was implemented, and any $\beta$ scores with a $P$ value greater than 0.05 in $12.5 \%$ of the samples were excluded. For correction of systematic differences between type I and type II probes, subset-quantile within array normalization (SWAN) was performed. Probes targeting single nucleotide polymorphisms and probes on sex chromosomes were removed from the downstream analysis. One specimen from a severe group was excluded from further analysis due to failing to provide optimal scores in quality checks. Bump hunter was used to detect differentially methylated regions and Bioconductor minfi package was employed to identify differentially methylated loci $[42,43]$. A $P$ value was calculated for the probes, and $P$ value over 0.05 was considered as not significant.

Validation of genome-wide methylation analysis was performed by bisulfite modification and quantitative pyrosequencing. DNA methylation values from HumanMethylation450 BeadChip array probes were compared with the data obtained from conventional quantitative pyrosequencing. For validation and verification experiments, bisulfite conversion of $1 \mu \mathrm{g}$ DNA was performed by EZ DNA Methylation GoldTM kit (Zymo Research, Cambridge Bioscience, UK). The conversion protocol was performed as follows: $98{ }^{\circ} \mathrm{C}$ for $10 \mathrm{~min}, 64{ }^{\circ} \mathrm{C}$ for $2.5 \mathrm{~h}$ and $4{ }^{\circ} \mathrm{C}$ holding step. Bisulfite-treated DNA was transferred to spin columns, desulphonated and eluted. Bisulfite-modified DNA was amplified by PCR with the assays and primers designed in our laboratory using Pyromark Assay Design Software SW2.0 (Qiagen, Mainz, Germany). PCR reaction was carried out using $12.5 \mu \mathrm{L}$ Hot star Taq Master Mix (Qiagen), 5-8 pmol of forward and reverse primers (one of each primer sets were biotin-labelled) in a $25-\mu \mathrm{L}$ volume. Forward, reverse and pyrosequencing primers were as follows: AATGGGTGATTTATGTTAGAAGAT, CTTTACCAAAT TCCTACCTAAAAA, ATATTGGTATTAGGTTTAAG for HDAC4; GGGTTTTGTTGTGGGAAATAGTA, CTCAA ССТССТСАССТСТTТСТАA, ССТСТААСАСТАТССА AAAT for HOXA2; and GGGTGGTGGTAGGAATTAAT AAGA, CAACCTCTCCAACCACAATTAATA, GGGATT TTTTGGTAAGGTA for PPP1R18.

Amplification was performed according to the following protocol: $95^{\circ} \mathrm{C}$ for $15 \mathrm{~min}, 50$ cycles of $95^{\circ} \mathrm{C}$ for $15 \mathrm{~s}$, annealing temperature of $55-60{ }^{\circ} \mathrm{C}$ for $30 \mathrm{~s}, 72{ }^{\circ} \mathrm{C}$ for $15 \mathrm{~s}$, followed by $72{ }^{\circ} \mathrm{C}$ for $5 \mathrm{~min}$. Biotin-labelled PCR products were captured by Streptavidin Sepharose beads (GE Healthcare, UK) and converted to single-stranded DNA by Vacuum Prep Tool (Qiagen). Sequencing primers were used to anneal single-stranded PCR product at $80{ }^{\circ} \mathrm{C}$ for $2 \mathrm{~min}$. Pyrosequencing was performed using Pyromark 96 MD system (Qiagen), and CpG methylation at each site was analysed by Pyro Q CG software (Qiagen). Mean methylation levels from four assays and methylation array were considered as concordant as absolute methylation differences were less than $10 \%$.

Immunohistochemistry for histone deacetylase 4 was performed on FFPE sections. Slides were dewaxed, rehydrated with alcohol and hydrogen peroxide was used to block endogenous peroxidase activity. Antigen retrieval was performed using citrate buffer (15-M103, Bio-Optica, Italy) in a microwave for $15 \mathrm{~min}$. Sections were incubated with primary antibody (anti-HDAC4 ab184983, Abcam) at $37{ }^{\circ} \mathrm{C}$ for $2 \mathrm{~h}$. Slides were washed in TBS-T and incubated with secondary antibody (biotinylated goat anti-polyvalent). After TBS-T washing, sections were incubated with streptavidin biotin peroxidase at room temperature for 10 min. HDAC positivity was shown by diaminobenzidine tetrahydrochloride (DAB). Slides were counterstained by haematoxylin.

\section{Statistical analysis}

Statistical analysis and graph construction were performed using SPSS software (IBM, USA) and GraphPad 
Prism Software (GraphPad, version 6.0). Results are shown as the mean value \pm confidence interval graphically. Means were compared via nonparametric tests (Mann-Whitney $U$ ) to define differences for not normally distributed data. Pearson's chi-square tests or Fisher's exact test was used for categorical variables. A $P$ value of less than 0.05 was considered statistically significant.

The study was performed in accordance to the Conference on Harmonization Guidelines for Good Clinical Practice and ethical guidelines of the Declaration of Helsinki. Ethical approval for the study protocol was granted by the Institutional Ethical Committee and Review Board (Atatürk Eğitim ve Araştırma Hastanesi, Izmir).

\section{Additional files}

Additional file 1: Figure S1. Flow chart demonstrating patients who underwent liver biopsy procedure and included into the study. (DOCX $43 \mathrm{~kb}$ )

Additional file 2: Table S1. Summary of differentially methylated regions. (DOCX $16 \mathrm{~kb}$ )

Additional file 3: Table S2. Hypermethylated probes in severe inflammation and fibrosis. (DOCX $18 \mathrm{~kb}$ )

Additional file 4: Table S3. Hypomethylated probes in severe inflammation and fibrosis. (DOCX $16 \mathrm{~kb}$ )

Additional file 5: Figure S2. Validation of the bisulfite modification and pyrosequencing assays for relevant loci in HDAC4, HOXA2 and PPPIR18 genes. Plots comparing $0,25,50,75$ and $100 \%$ of methylated DNA with obtained methylation results are shown; only assays with an acceptable performance ( $r^{2}$ values over 0.95) were used in this study. (TIF $149 \mathrm{~kb}$ )

Additional file 6: Figure S3. Histone deacetylase 4 immunohistochemistry in mild and severe disease: HDAC4 is highly expressed in advanced inflammation and fibrosis. Representative $\times 200$ pictures of HDAC4 immunohistochemistry from five mild (fibrosis stage $\leq 1$ ) and five severe (fibrosis stage $\geq 4$ ) chronic liver disease due to hepatitis B infection. DAB-positive staining pattern was detected in myofibroblasts, inflammatory cells and hepatocytes in or near to fibrosis tracts. (TIF $1747 \mathrm{~kb}$ )

Additional file 7: Table S4. Demographic, clinical and laboratory characteristics of the non-progressors and progressors in serial biopsies. (DOCX $18 \mathrm{~kb}$ )

Additional file 8: Figure S4. Change in hepatic DNA methylation levels between follow-up and initial biopsies of non-progressors (no increase in stage of fibrosis) and progressors ( $\geq 1$ stage increase in severity of fibrosis). Boxes and bars represent the means and standard error of cytosine methylation at HDAC4 (a, b), HOXA2 (c) and PPP1R18 (d) genes. (TIF $4146 \mathrm{~kb})$

\section{Abbreviations \\ CpG: cytosine-guanine dinucleotide; HBV: hepatitis B virus; HDAC4: histone deacetylase 4; HIV: human immunodeficiency virus; HLA-DQA1: major histocompatibility complex, class II, DQ alpha 1; HOXA2: homeobox A2; PNPLA3: patatin-like phospholipase domain-containing protein 3; PPP1R18: protein phosphatase 1, regulator subunit 18; TM6SF2: transmembrane 6 superfamily member 2; TMEM57: transmembrane protein 57}

\section{Competing interests}

The authors declare that they have no competing interests.

\section{Authors' contributions}

$M Z$ and TH performed the majority of the experiments. MZ, SV, TH, GZ and JCM analysed the data. SK, AAS, FC and AA carried out the histological grading and staging of the liver disease. SV and BU established the chronic hepatitis B cohort and provided the clinical data. MB carried out bioinformatics analysis and statistical support. MZ and JM designed the study and wrote the manuscript. All authors read and approved the final manuscript.

\section{Acknowledgements}

We thank Oktay Tarhan M.D. and Nasuhi Engin Aydın M.D. for assistance with the clinical data collection.

\section{Funding}

This work was supported by grants from the European Association for the Study of the Liver, Sheila Sherlock Physician Scientist Fellowship (to MZ) and European Commission, Horizon 2020 Marie Curie Sklodowska Individual Fellowship (to MZ) and NIHR Newcastle Biomedical Research Centre (to JM).

\section{Author details}

'Institute of Cellular Medicine, Newcastle University, Newcastle upon Tyne, UK. ${ }^{2}$ School of Medicine, Koç University Hospital, Koç University, 4th floorM-4220. Davutpaşa Caddesi no: 4, 34010 Istanbul, Turkey. ${ }^{3}$ Department of Gastroenterology and Hepatology, Katip Çelebi University, Atatürk Eğitim ve Araştırma Hastanesi, Izmir, Turkey. ${ }^{4}$ Department of Pathology, Katip Çelebi University, Atatürk Eğitim ve Araştırma Hastanesi, Izmir, Turkey.

${ }^{5}$ Bioinformatics Support Unit, Faculty of Medical Sciences, Newcastle University, Newcastle upon Tyne, UK. ${ }^{6}$ Human Nutrition Research Centre, Newcastle University, Newcastle upon Tyne, UK.

Received: 11 December 2015 Accepted: 28 April 2016 Published online: 05 May 2016

\section{References}

1. Liaw YF, Chu CM. Hepatitis B virus infection. Lancet. 2009:373(9663):582-92.

2. Lozano R, Naghavi M, Foreman K, Lim S, Shibuya K, Aboyans V, et al. Global and regional mortality from 235 causes of death for 20 age groups in 1990 and 2010: a systematic analysis for the Global Burden of Disease Study 2010. Lancet. 2012:380(9859):2095-128.

3. Trepo C, Chan HL, Lok A. Hepatitis B virus infection. Lancet. 2014;384(9959): 2053-63.

4. McMahon BJ. The natural history of chronic hepatitis B virus infection. Hepatology. 2009:49(5 Suppl):S45-55

5. Friedman SL, Sheppard D, Duffield JS, Violette S. Therapy for fibrotic diseases: nearing the starting line. Sci Transl Med. 2013;5(167):167sr1.

6. Pinzani M, Rombouts $\mathrm{K}$, Colagrande S. Fibrosis in chronic liver diseases: diagnosis and management. J Hepatol. 2005;42(1):S22-36.

7. Boursier J, Louvet A. Liver fibrogenesis and genetic factors. Clin Res Hepatol Gastroenterol. 2011;35 Suppl 1:S3-9.

8. Liu YL, Reeves HL, Burt AD, Tiniakos D, McPherson S, Leathart JB, et al. TM6SF2 rs58542926 influences hepatic fibrosis progression in patients with non-alcoholic fatty liver disease. Nat Commun. 2014:5:4309.

9. Patin E, Kutalik Z, Guergnon J, Bibert S, Nalpas B, Jouanguy E, et al. Genome-wide association study identifies variants associated with progression of liver fibrosis from HCV infection. Gastroenterology. 2012; 143(5):1244-52. e1-12

10. Huang H, Shiffman ML, Friedman S, Venkatesh R, Bzowej N, Abar OT, et al A 7 gene signature identifies the risk of developing cirrhosis in patients with chronic hepatitis C. Hepatology. 2007:46(2):297-306.

11. Valenti L, Al-Serri A, Daly AK, Galmozzi E, Rametta R, Dongiovanni P, et al. Homozygosity for the patatin-like phospholipase-3/adiponutrin I148M polymorphism influences liver fibrosis in patients with nonalcoholic fatty liver disease. Hepatology. 2010:51(4):1209-17.

12. Eslam M, Hashem AM, Leung R, Romero-Gomez M, Berg T, Dore GJ, et al. Interferon-lambda rs12979860 genotype and liver fibrosis in viral and nonviral chronic liver disease. Nat Commun. 2015;6:6422.

13. Egger $G$, Liang $G$, Aparicio A, Jones PA. Epigenetics in human disease and prospects for epigenetic therapy. Nature. 2004;429(6990):457-63.

14. Feinberg AP. Epigenetics at the epicenter of modern medicine. JAMA. 2008; 299(11):1345-50

15. Murphy SK, Yang H, Moylan CA, Pang H, Dellinger A, Abdelmalek MF, et al. Relationship between methylome and transcriptome in patients with nonalcoholic fatty liver disease. Gastroenterology. 2013;145(5):1076-87.

16. Zeybel M, Hardy T, Robinson SM, Fox C, Anstee QM, Ness T, et al. Differential DNA methylation of genes involved in fibrosis progression in 
non-alcoholic fatty liver disease and alcoholic liver disease. Clin Epigenetics. 2015;7(1):25.

17. Kaneto H, Sasaki S, Yamamoto H, Itoh F, Toyota M, Suzuki H, et al. Detection of hypermethylation of the p16(INK4A) gene promoter in chronic hepatitis and cirrhosis associated with hepatitis B or C virus. Gut. 2001;48(3):372-7.

18. Vivekanandan P, Daniel HD, Kannangai R, Martinez-Murillo F, Torbenson M. Hepatitis $B$ virus replication induces methylation of both host and viral DNA. J Virol. 2010;84(9):4321-9.

19. Ancey PB, Testoni B, Gruffaz M, Cros MP, Durand G, Le Calvez-Kelm F, et al. Genomic responses to hepatitis B virus (HBV) infection in primary human hepatocytes. Oncotarget. 2015;6(42):44877-91.

20. Okamoto Y, Shinjo K, Shimizu Y, Sano T, Yamao K, Gao W, et al. Hepatitis virus infection affects DNA methylation in mice with humanized livers. Gastroenterology. 2014;146(2):562-72.

21. Aran D, Toperoff G, Rosenberg M, Hellman A. Replication timing-related and gene body-specific methylation of active human genes. Hum Mol Genet. 2011;20(4):670-80.

22. Glenisson W, Castronovo V, Waltregny D. Histone deacetylase 4 is required for TGFbeta1-induced myofibroblastic differentiation. Biochim Biophys Acta. 2007;1773(10):1572-82.

23. Liu Y, Wang Z, Wang J, Lam W, Kwong S, Li F, et al. A histone deacetylase inhibitor, largazole, decreases liver fibrosis and angiogenesis by inhibiting transforming growth factor-beta and vascular endothelial growth factor signalling. Liver Int. 2013;33(4):504-15.

24. Niki T, Rombouts K, De Bleser P, De Smet K, Rogiers V, Schuppan D, et al. A histone deacetylase inhibitor, trichostatin $A$, suppresses myofibroblastic differentiation of rat hepatic stellate cells in primary culture. Hepatology. 1999;29(3):858-67.

25. Mannaerts I, Nuytten NR, Rogiers V, Vanderkerken K, van Grunsven LA, Geerts A. Chronic administration of valproic acid inhibits activation of mouse hepatic stellate cells in vitro and in vivo. Hepatology. 2010;51 (2):603-14.

26. Cedar $\mathrm{H}$, Bergman $\mathrm{Y}$. Linking DNA methylation and histone modification: patterns and paradigms. Nat Rev Genet. 2009;10(5):295-304.

27. Lopez-Rodriguez R, Hernandez-Bartolome A, Borque MJ, Rodriguez-Munoz Y, Martin-Vilchez S, Trapero-Marugan M, et al. Polymorphisms in histone deacetylases improve the predictive value of $\mathrm{LL}-28 \mathrm{~B}$ for chronic hepatitis $\mathrm{C}$ therapy. Genes Immun. 2013;14(5):317-24.

28. Bocker MT, Tuorto F, Raddatz G, Musch T, Yang FC, Xu M, et al. Hydroxylation of 5-methylcytosine by TET2 maintains the active state of the mammalian HOXA cluster. Nat Commun. 2012;3:818.

29. Shu Y, Wang B, Wang J, Wang JM, Zou SQ. Identification of methylation profile of HOX genes in extrahepatic cholangiocarcinoma. World J Gastroenterol. 2011;17(29):3407-19.

30. Kao SC, Chen CY, Wang SL, Yang JJ, Hung WC, Chen YC, et al. Identification of phostensin, a PP1 F-actin cytoskeleton targeting subunit. Biochem Biophys Res Commun. 2007;356(3):594-8.

31. Lin YS, Huang KY, Wang TF, Huang HL, Yu HC, Yen JY, et al. Immunolocalization of phostensin in lymphatic cells and tissues. J Histochem Cytochem. 2011; 59(8):741-9.

32. Zeybel M, Hardy T, Wong YK, Mathers JC, Fox CR, Gackowska A, et al. Multigenerational epigenetic adaptation of the hepatic wound-healing response. Nat Med. 2012;18(9):1369-77.

33. Schmetz A, Lammert F, Weber SN. 'Lucky grandchildren': inbred mice whose grandparents developed liver fibrosis appear to be protected against the same disease. Hepatology. 2014;60:573a-a.

34. Jaffe AE, rrizarry RA. Accounting for cellular heterogeneity is critical in epigenome-wide association studies. Genome Biol. 2014;15(2):R31.

35. Bedossa P, Dargere D, Paradis V. Sampling variability of liver fibrosis in chronic hepatitis C. Hepatology. 2003;38(6):1449-57.

36. Zeybel M, Mann DA, Mann J. Epigenetic modifications as new targets for liver disease therapies. J Hepatol. 2013;59(6):1349-53.

37. Zhao Q, Fan YC, Zhao J, Gao S, Zhao ZH, Wang K. DNA methylation patterns of peroxisome proliferator-activated receptor gamma gene associated with liver fibrosis and inflammation in chronic hepatitis B. J Viral Hepat. 2013;20(6):430-7.

38. Hardy T, Zeybel M, Day CP, Dipper C, Masson S, McPherson S, et al. Plasma DNA methylation: a potential biomarker for stratification of liver fibrosis in non-alcoholic fatty liver disease. Gut. 2016. doi: 10.1136/gutjnl-2016-311526.

39. Ishak K, Baptista A, Bianchi L, Callea F, De Groote J, Gudat F, et al. Histological grading and staging of chronic hepatitis. J Hepatol. 1995;22(6):696-9.
40. Gentleman RC, Carey VJ, Bates DM, Bolstad B, Dettling M, Dudoit S, et al. Bioconductor: open software development for computational biology and bioinformatics. Genome Biol. 2004;5(10):R80.

41. Storey JD, Tibshirani R. Statistical significance for genome-wide studies. PNAS. 2003;100:9440-5.

42. Aryee MJ, Jaffe AE, Corrada-Bravo H, Ladd-Acosta C, Feinberg AP, Hansen KD, et al. Minfi: a flexible and comprehensive Bioconductor package for the analysis of Infinium DNA methylation microarrays. Bioinformatics. 2014;30(10): $1363-9$.

43. Jaffe AE, Murakami P, Lee H, Leek JT, Fallin MD, Feinberg AP, et al. Bump hunting to identify differentially methylated regions in epigenetic epidemiology studies. Int J Epidemiol. 2012;41(1):200-9.

\section{Submit your next manuscript to BioMed Central and we will help you at every step:}

- We accept pre-submission inquiries

- Our selector tool helps you to find the most relevant journal

- We provide round the clock customer support

- Convenient online submission

- Thorough peer review

- Inclusion in PubMed and all major indexing services

- Maximum visibility for your research

Submit your manuscript at www.biomedcentral.com/submit
Biomed Central 